This item was submitted to Loughborough's Research Repository by the author.

Items in Figshare are protected by copyright, with all rights reserved, unless otherwise indicated.

\title{
Effect of geometry on the performance of intermingling nozzles
}

PLEASE CITE THE PUBLISHED VERSION

https://doi.org/10.1177/004051759906900801

PUBLISHER

Sage

VERSION

AM (Accepted Manuscript)

PUBLISHER STATEMENT

This work is made available according to the conditions of the Creative Commons Attribution-NonCommercialNoDerivatives 4.0 International (CC BY-NC-ND 4.0) licence. Full details of this licence are available at: https://creativecommons.org/licenses/by-nc-nd/4.0/

\section{LICENCE}

CC BY-NC-ND 4.0

\section{REPOSITORY RECORD}

Versteeg, Hendrik K., Memis Acar, and Sule Bilgin. 2019. "Effect of Geometry on the Performance of Intermingling Nozzles". figshare. https://hdl.handle.net/2134/26934. 


\title{
Effect of Geometry on the Performance of Intermingling Nozzles
}

\author{
H.K. VERSTEEG AND M. ACAR \\ Department of Mechanical Engineering, Loughborough University of Technology, Loughborough, Leicestershire \\ LEJ 1 3TU, United Kingdom \\ S. BILGIN \\ Department of Textile Engineering, Uludag University, Gorukle, 16059 Bursa, Turkey ${ }^{1}$
}

\begin{abstract}
This study investigates the effect of nozzle geometry on the intermingling process. The dimensions of intermingling nozzles with single air inlets extended across the width of a rectangular yam channel are systematically varied. Nozzles with this cross-sectional shape prove to be easy to manufacture and efficient at intermingling. The performance is evaluated by visually inspecting the intermingled yarns and by measuring the nip frequency. We have found that the performance of nozzles with large inlet widths is weakly dependent on yam channel geometry. The performance of nozzles with the smallest a.ir inlet widths, on the other hand, is sensitive to yarn channel geometry. The smallest and largest yam channels we have considered give poor intermingling results. Control of the yarn path is beneficial for the success and consistency of the intermingling process. Using yarn guides to create a diagonal yarn path across the nozzle has the additional advantage of decreasing noise production. Our extended air inlet slot ensures continuous exposure of the yarn to the supply air stream across the entire width of the yarn channel in this arrangement. We also compare our designs with four industrial nozzles under identical process conditions. This study reveals similar trends for nip frequency and power consumption. The results agree with the broad trend established in the geometry study that the shape of the yam channel is not critical, provided the air inlet is large enough.
\end{abstract}

Intermingling is a mechanical technique to impart desirable cohesion characteristics to synthetic filament yarns at relatively low running costs. The process uses an air-jet delivered by a nozzle to entangle/interlace the constituent filaments of a continuous yarn, producing intermittent nodes, i.e., entangled sections (usually known as nips) at reasonably regular intervals with un- disturbed (unentangled) sections between them. This technique e is widely used in industry owing to its low cost compared to alternatives such as sizing and twisting.

The first patent for an intermingling nozzle was acquired by DuPont in 1961 [4], but much of the published scientific work is relatively recent. The simplest intermingling nozzle consists of a yarn channel with an air inlet hole in the middle. A jet of air emerging from this inlet hole usually impinges at right angles onto the yarn travelling through the channel. Most researchers used this simplest nozzle configuration as a starting point, and their main concern has been to improve nip frequency and nip regula1ity, the two key performance indicators.

Schubert [8] found that a single air inlet leads to a higher nip frequency than multiple, narrower inlets with the same air consumption. Moreover, he found that an oblique air inlet increases nip frequency but dis tur s yarn tension, and that reductions in the channel cross-sectional area adversely affect the nozzle performance. Finally, he claimed that nozzles with rectangular cross sections produce greater intermingling density than those with circular cross sections. Weinsdoerfer's work [9] agreed with this conclusion and found that nozzles with rectangular yarn channels have superior performance compared with semicircular ones, which they are better than circular channels. Luenenschloss and Zilg [7] reported that shorter yarn channels always result in lower intermingling density. However, Lazauska s et al. [6] contradicted this finding and claimed that nip frequency increases with a decreased yarn channel length. They also reported that an 
increase in cross-sectional area allows the yam to move out of the intense influence of the incoming air jet.

Basu [1] reported a study in which the length of an intermingling nozzle was varied along with process parameters such as the air supply pressure. He found that an increase in nozzle length gave rise to increased nip frequency. The effect of air supply pressure was rather more complex. At lower supply pressures, nip frequency increased with pressure, but at higher values of supply pressure this trend reversed. Iemoto et al. [5] also explored, among many other process parameters, the effect of air pressure on nip frequency for an intermingling nozzle with circular cross section, and they found increased nip frequency with increasing pressure.

Demir [2] catalogued the intermingling nozzle geometries that are used in industry. The most common yarn channel shape is circular, but there are also cross sections with semi-circular, rectangular, and triangular shapes. The cross section of the yarn channel is normally uniform throughout the length of the nozzle, but there are also variations such as diverging yarn inlets or outlets, step enlargements, or a wider yarn channel section at the air inlet region. The yarn channel often contains a narrow slit for threading the yam. Although some industrial nozzles have slightly inclined or multiple air inlets, most mingling nozzle designs have a single air inlet at right angles to the yarn channel. The air is supplied at constant pressure, which creates a steady flow. Some nozzles have vents to partially exhaust the air before it reaches the end planes of the nozzle. These are used to achieve an early expansion of the flow in the yarn channels, which is believed to be of benefit to nip creation.

With so many different geometries adopted by industry, it is perhaps not surprising that work on the effect of geometry on intermingling nozzle performance has been so fragmentary. It is our aim to report on a study that systematically investigates geometry effects on nip frequency. The investigations center on a series of intermingling nozzles with rectangular yarn channel cross sections. We pay particular attention to controlling the yam path by means of yarn guides and ensuring continuous contact between the inlet air jet and the yarn by means of a novel air inlet arrangement that always covers the entire yarn channel. We also compare the performance of our nozzles with four typical industrial intermingling nozzles.

\section{Nozzle Geometry}

Rectangular yarn channels have been reported to per- form well (Schubert [8], Weinsdoerfer [9]), and so we selected them for this work in conjunction with a single extended air inlet hole. The basic design, shown in Figure 1, has a simple two-part structure and is very easy to manufacture. It consists of two pieces: the cover with extended inlet hole connected to the compressed air supply, and the base with the yarn channel.

The air inlet is at right angles to the yarn channel and is located midway along the length of the nozzle, creating a symmetrical geometry. The extended inlet hole, a novel feature of our design, covers the entire width of the yarn channel and ensures that all constituent filaments of the yarn, regardless of their position within the yarn channel, are always subjected to the incoming airflow. We believe this improved contact between yarn and air enhances the consistency of the intermingling process. Our design of a nozzle with an extended air inlet also eliminates the need for precise adjustments of the relative positions of the base and cover. Figure I shows the nozzle base and cover in an open configuration.

We investigated the effects of the width and depth of the yarn channel and the width of the air inlet hole of the nozzles by systematically varying the se dimensions. We tested three different air inlet slot widths of $0.7,1.0$, and $1.5 \mathrm{~mm}$ with and without air vents. We used a total of six different cover pieces with yarn channel width s of 1.0, 1.5, 2.0, and $2.5 \mathrm{~mm}$ and depths of 1.5 and $2.0 \mathrm{~mm}$, and studied a total of eighteen nozzle geometry combinations. All nozzle s were designed and manufactured with identical lengths of $20 \mathrm{~mm}$. 


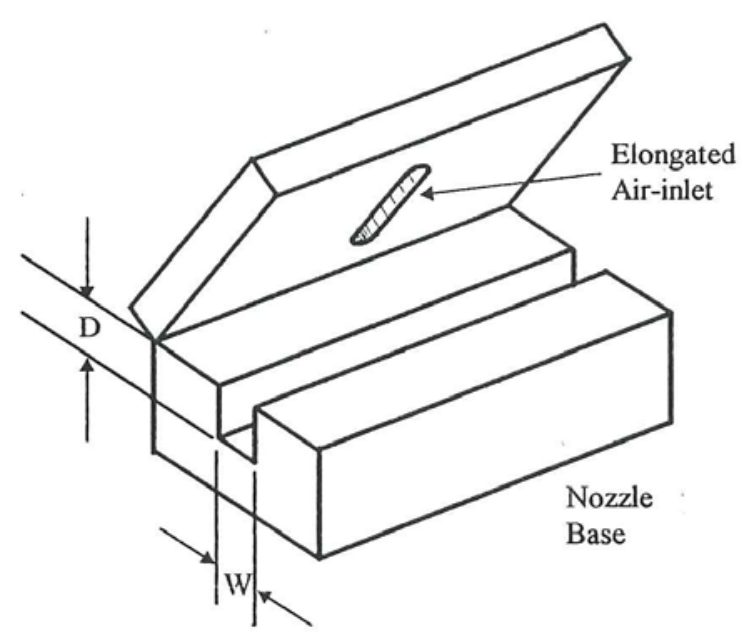

FIGURE 1. Geometry of experimental rectangular nozzles.

\section{Experimental Procedure}

A schematic sketch illustrates the experimental set-up (Figure 2). A yarn throughput speed of $600 \mathrm{~m} / \mathrm{min}$ was selected to represent industrial production rates. The nozzles were tested by placing them between two sets of yarn transprn1 rollers with individual speed controls. The independently driven rollers enabled the pre-textured yarn to be stretched or overfed by changing the relative speed of the rollers to maintain a suitable tension between them. Preliminary trials showed that an overfeed ratio within the 0-1 \% range produced nips most efficiently. We maintained this range of overfeeds throughout our tests.

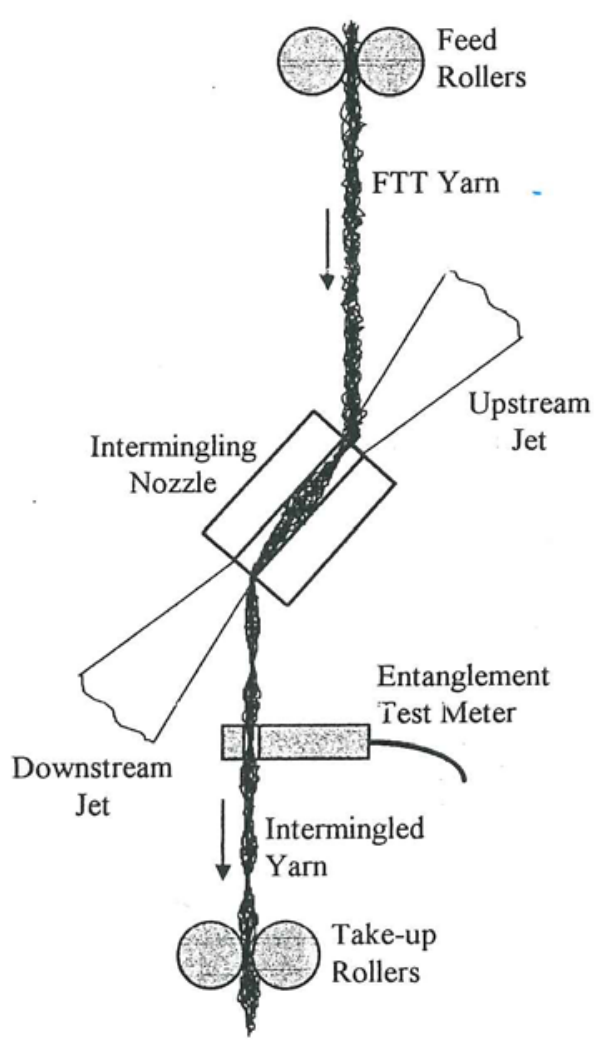

FIGURE 2. Schematic of the experimental set-up of the intermingling process and diagonal yarn path. 
A pre-false-twist textured polyester PES 167/30 yarn was used for the intermingling tests. The air inlet pressure of the intermingling processes varied between 1.5 and 4 bar gauge in increments of 0.5 bar. Higher air pressures have not been found to be beneficial to the intermingling process. They increase the compressed air consumption as well as the likelihood of filament dam- age and occasional yarn breakage. Air pressure was measured with a Bourdon gauge to an accuracy of \pm 0.1 bar. The air flow rate was measured with a Platon rotameter with an accuracy of approximately $\pm 5 \%$ at the lowest recorded flow rates and better than this at the higher flows.

Initially, the nozzle axis was aligned with the yarn path and the yarn was allowed to travel freely without yarn guides. Under these conditions, it was difficult to produce nips consistently. We observed a marked improvement when yarn guides were positioned at both ends of the nozzle in such a way as to allow the yarn to enter and leave the nozzle at an angle of approximately $45^{\circ}$ to the nozzle axis. The yarn was thus forced to travel diagonally through the nozzle (see Figure 2) in a firmly controlled yarn path to ensure continuous interaction with the incoming air jet provided by the extended inlet hole at all times. This prevented the yarn from following a path to one side of the rectangular nozzle outside the maximum influence of the air stream. The additional and important benefit of this yarn guide position outside the emerging jets was that it significantly reduced noise generation (Dorney et al. [3]).

We assessed the intermingling performance of the nozzles by measuring nip frequency during the process with a portable Lee Consultants entanglement test meter type 2 . We also obtained the nip frequency of a number of selected yarn samples by a manual count to verify the accuracy of the readings.

\section{Results and Discussion}

The main body of intermingling data is presented in Table I. The details of each yarn channel de sign are denoted in the heading of the table by depth $\mathrm{D}$ and width $\mathrm{W}$ in $\mathrm{mm}$. Each data point reports the average of ten intermingling trials at identical process conditions.

Within the range of pressures tested, the nip frequency initially rapidly increases with increasing supply pressure up to around 2.5 bars and then reaches an almost constant value for most nozzles. Exceptions to this general trend are the nozzles with small air inlets - s mall air inlet slot width or narrow main channel - for which the nip frequency generally continues to rise with pressure.

The data in the table also illustrate that, except for the smallest yarn channel (1.5 ri1m deep and $1.0 \mathrm{~mm}$ wide) and the largest yarn channel (2.0 $\mathrm{mm}$ deep and $2.5 \mathrm{~mm}$ wide), the nip frequency as a function of supply pressure is not much affected by the air inlet slot width. The remaining data trends can be summarized as follows: Nozzle combinations with channels $1.5 \mathrm{~mm}$ wide and 1.5 and $2.0 \mathrm{~mm}$ deep give the highest nip frequencies $(80-100 \mathrm{nips} / \mathrm{m})$ in the range of 2.5 to 4 bars. For these main channel dimensions, inlet slots of 0.7 and $1.0 \mathrm{~mm}$ wide give the best performance. The nozzle with the narrowest yarn channel width, $1.0 \mathrm{~mm}$, gives generally low nip frequencies, particularly at the lower end of the pressure range. The nozzle with the largest yarn channel, $2.0 \mathrm{~mm}$ deep and $2.5 \mathrm{~mm}$ wide, produces reasonable nip counts - around 80 per $\mathrm{m}$ - in conjunction with 1.0 and $1.5 \mathrm{~mm}$ wide air inlets. In combination with the $0.7 \mathrm{~mm}$ air inlet width, this channel gives poor results 20-30 nips/m. Tests with vented main channels do not show significant differences in the nip frequencies measured with those of nozzle s without vents.

Table I illustrates this point for one of the designs tested.

The performance of a given nozzle design in relation to the operating parameters is use fully displayed by the relationship between nip frequency and air supply pressure. However, this is not an entirely satisfactory basis for comparing widely different nozzle designs. The variable running costs of the intermingling process are determined by power consumption. The bene fits of a small increase in achievable nip frequency ma y very well be offset by a large increase in compressed air consumption. 
Thus, we display in Figure 3 the nip frequency as a function of the theoretical compressed air power consumption (in Watts), evaluated as follows:

$$
\text { Power }=M p_{a t m} / \rho_{a t m}(\gamma /(\gamma-1))\left(\left(p / p_{a t m}\right)^{(\gamma-1) / \gamma}-1\right),
$$

where $M$ = air mass flow rate $(\mathrm{kg} / \mathrm{s}), p=$ supply pressure $(\mathrm{Pa}$ abs $), p_{a t m}=$ atmospheric pressure $(\mathrm{Pa}$ abs), $\rho_{\text {atm }}=$ density of atmospheric air $\left(\mathrm{kg} / \mathrm{m}^{3}\right)$, and $\gamma=$ specific heat ratio $=1.4$ for air.

TABLE I. Nip frequency and air consumption of experimental rectangular nozzles.

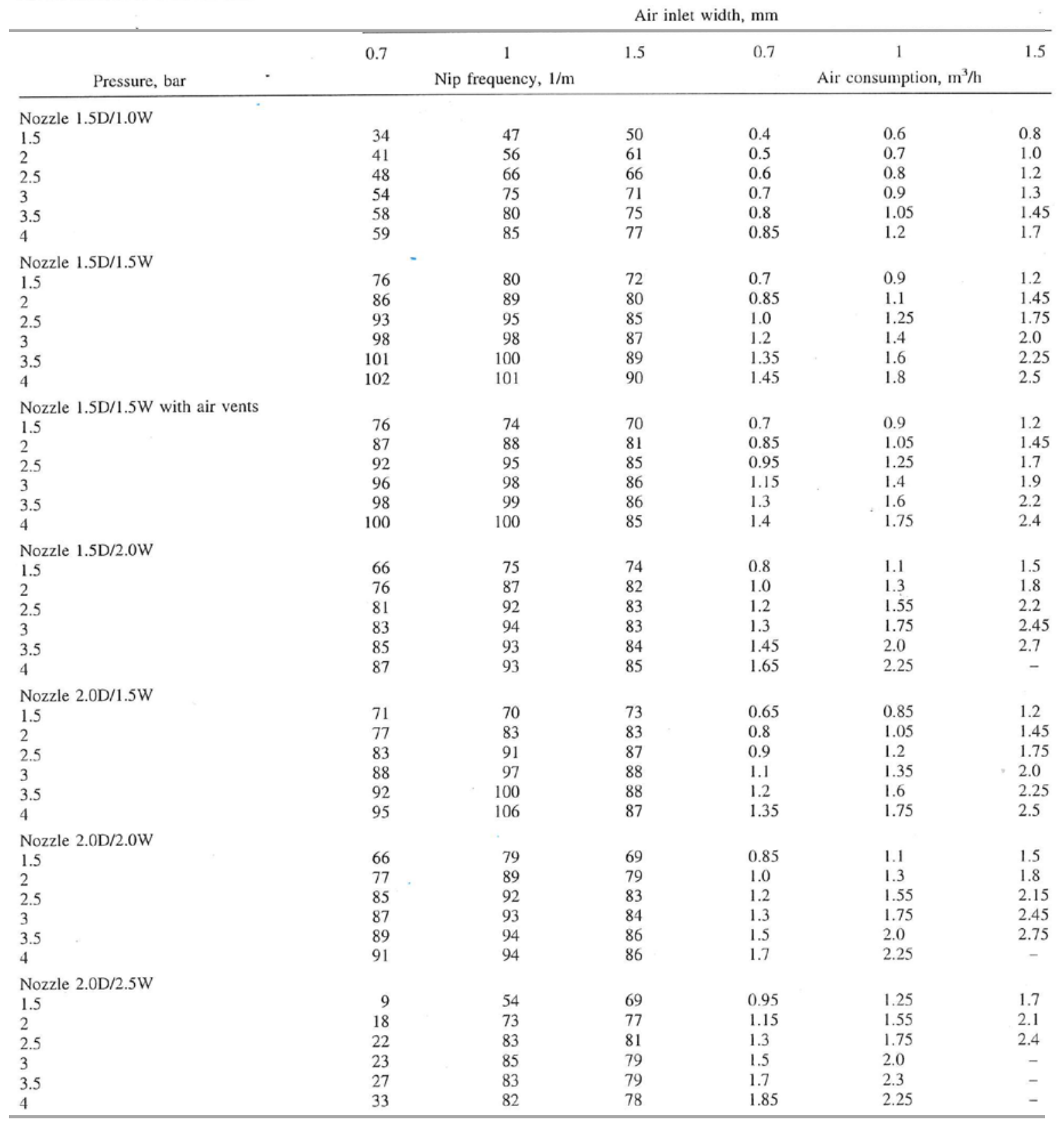



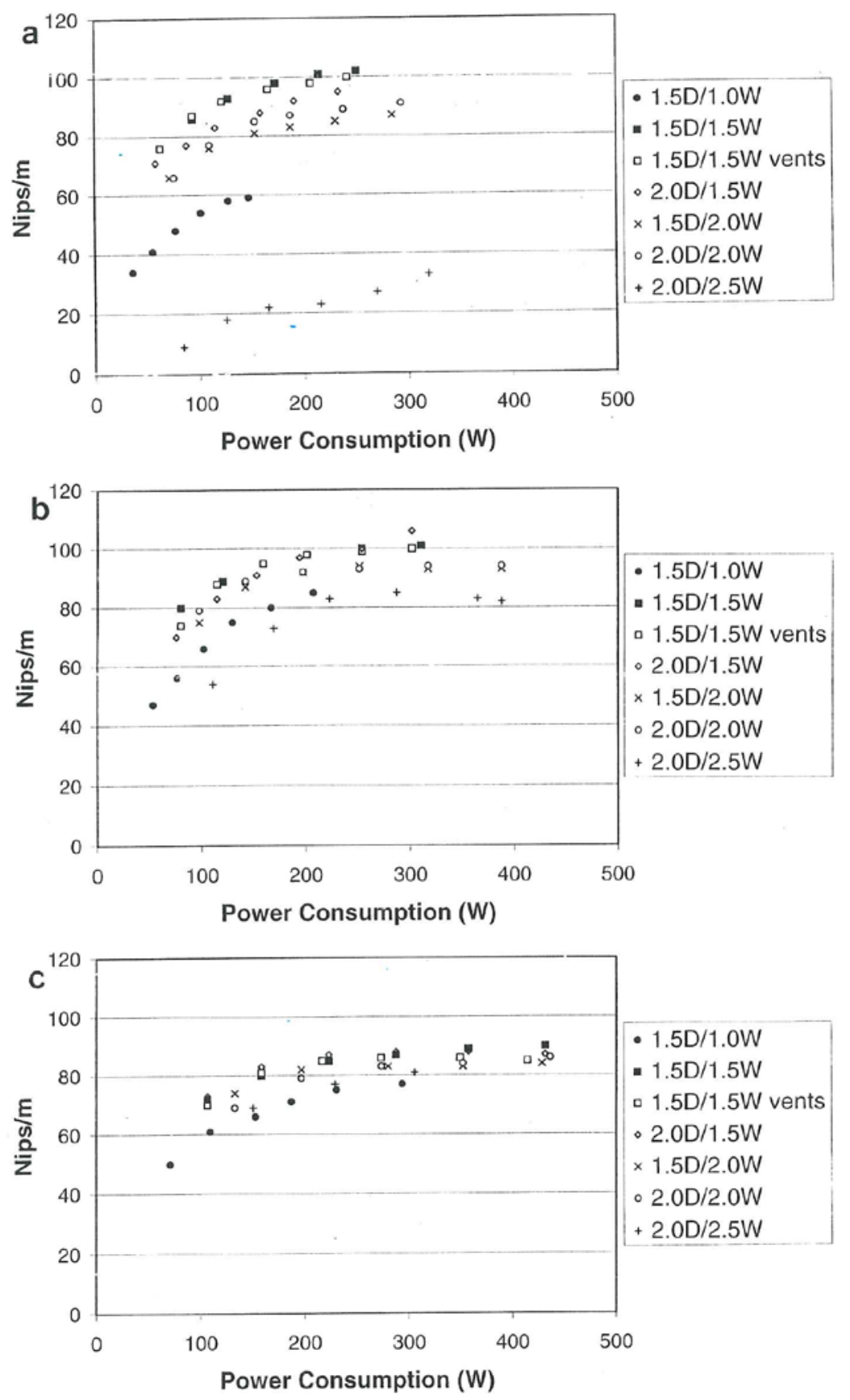

FIGURE 3. Nip frequency versus fluid power consumption for rectangular nozzles: air inlet slot width of (a) $0.7 \mathrm{~mm}$, (b) $1.0 \mathrm{~mm}$, (c) $1.5 \mathrm{~mm}$.

The actual power consumption, and hence the running cost attributable to the process, can be obtained by dividing the value from Equation 1 by the isentropic efficiency of the compressor. This will vary from device to device, so here we use the theoretical power for comparative purposes. The diagrams show the relationship be- tween nip frequency and theoretical power consumption for the various yam channels, while the inlet slot width is kept constant. As before, we find increased nip frequency at low power consumption and a region of more or less constant nip frequency at higher power consumption. However, there is an important difference: nozzles with small air inlets have low air consumption at a given pressure, so this method can account for the resulting advantage in running costs. We highlight the following trends: Nip frequency depends strongly on yarn channel dimensions for nozzles with the smallest air inlet slot width $(0.7 \mathrm{~mm})$. The smallest and largest yarn channels give very low nip counts. The best nozzles give 
peak nip frequencies ranging from 80 to 100 in conjunction with power requirements of around 125 to $300 \mathrm{~W}$. The performance of nozzles with a large air inlet slot width $(1.5 \mathrm{~mm})$ is not significantly affected by yarn channel dimensions. All yam channels used in conjunction with this air inlet width give peak nip frequencies in the range of 80 to 90 nips $/ \mathrm{m}$ for power consumption from 225 to $450 \mathrm{~W}$. The results show that the yarn channels with widths of $1.5 \mathrm{~mm}$ and depth s of 1.5 and $2.0 \mathrm{~mm}$ give the highest nip frequency for all three inlet slot widths on the basis of power consumption.

We have also compared the performance of our best rectangular nozzle $\mathrm{s}$ with four industrial nozzles under identical process conditions. A brief summary of each of the nozzle $s$ is as follows: Nozzle I: triangular channel, base $3 \mathrm{~mm}$ wide, $1.2 \mathrm{~mm}$ deep; perpendicular circular air inlet of 1.6 $\mathrm{mm}$ diameter. Nozzle 2: stepped channel, width variable between 0.95 to $2.1 \mathrm{~mm}$; perpendicular circular air inlet of $1.1 \mathrm{~mm}$ diameter. Nozzle 3: circular sector channel (approximately 270 2.4 $\mathrm{mm}$ diameter, mm deep; elliptical air inlet with major axis $2 \mathrm{~mm}$ and minor axis $1 \mathrm{~mm}$, inlet angle slightly smaller than $90^{\circ}$. Nozzle 4: triangular channel, base $2.6 \mathrm{~mm}, 0.8 \mathrm{~mm}$ deep; perpendicular circular air inlet of $1.0 \mathrm{~mm}$ diameter. Best L'boro rectangular nozzle: square channel 1.5 X $1.5 \mathrm{~mm}$; perpendicular rectangular air inlet $0.7 \mathrm{~mm}$ wide.

Figure 4 gives the nip frequency as a function of the power consumption on for each nozzle. The data reveal that the performance of the experimental rectangular nozzles compares favorably with the best of the industrial nozzles tested. The nip counts of nozzle 2 and the L'boro nozzle are practically equal in the power consumption range below $150 \mathrm{~W}$, and at higher power consumption the maximum nip frequency of our experimental nozzle is $10 \%$ higher than that of the best of the four industrial nozzles.

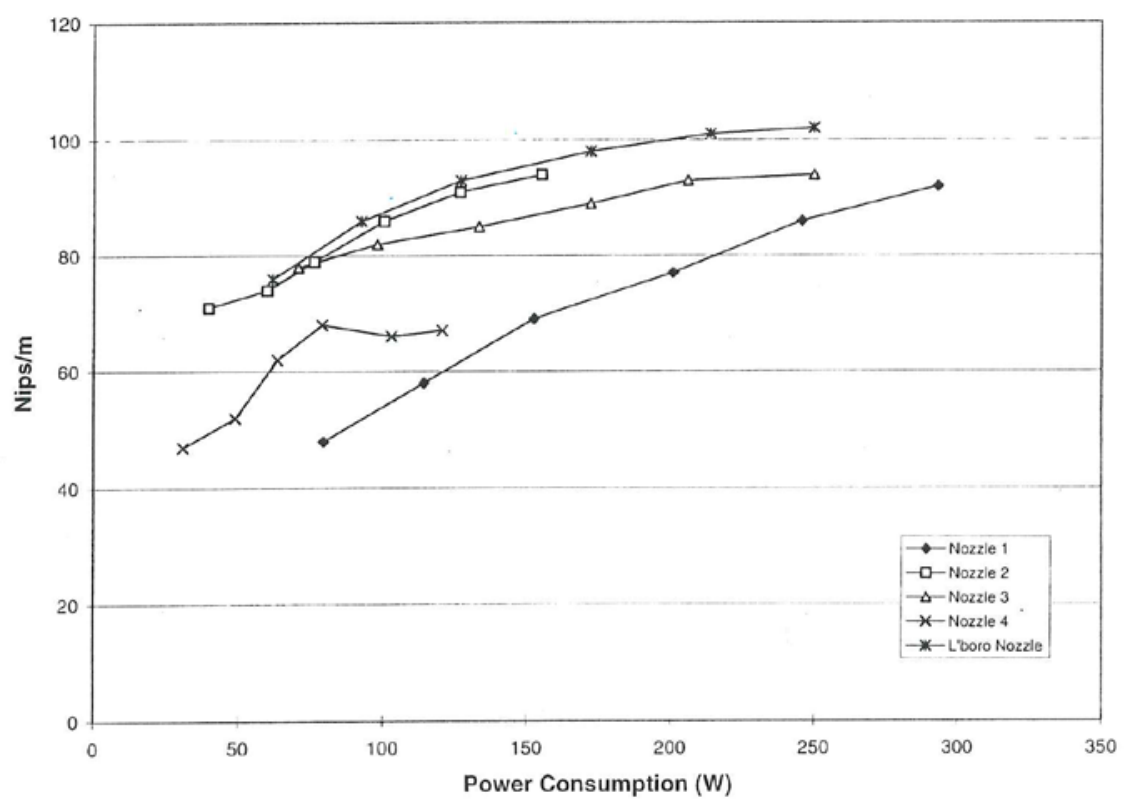

FIGURE 4. Performance comparison of four industrial nozzles with rectangular nozzle.

Care must of course be taken in extrapolating our results for rectangular main channels with specialized air inlet shapes,-but it is interesting to note that the air inlet area of the best industrial nozzle (nozzle 2) is close to that of the Loughborough nozzle. A comparison of the crosssectional areas of the air inlets for the five nozzles shows that the inlet area $\left(\mathrm{mm}^{2}\right)$ for nozzle 1 is 2.0 , for nozzle 2 is 0.95 , for nozzle 3 is 1.57 , for nozzle 4 is 0.79 , and for the L'boro nozzle is 1.05 . 
Nozzles 1 and 3 give nip frequencies that are comparable to those achieved with rectangular nozzles with air inlet widths of 1.0 and $1.5 \mathrm{~mm}$, i.e., with similar inlet cross-sectional areas. Nozzle 4 produces a modest nip frequency, but at low power consumption throughout the range of pressures tested.

These data trends agree reasonably with those from our systematic study of rectangular nozzles. Both suggest that the wide variety of shapes in use in industry can be explained by the notion that the actual shape of the yam channel cross section is probably not too critical as regards the performance of the nozzle, provided the air inlet is large enough to promote sufficient air flow in contact with the yarn. On the other hand, high nip frequencies are possible at lower air consumption (i.e., at lower operating costs) by carefully matching a small air inlet with the main channel dimensions.

\section{Conclusions}

The main conclusions of our work on the experimental rectangular nozzles can be summarized as follows: For a given nozzle design, nip frequency generally increases with air supply pressure within the range of pressures from 1.5 to 4 bar we tested. The effect of nozzle geometry is only slight if the performance is assessed on the basis of constant pressure. Only the smallest $(1.5 \mathrm{~mm}$ deep, $1.0 \mathrm{~mm}$ wide) and largest ( $2.0 \mathrm{~mm}$ deep, $2.5 \mathrm{~mm}$ wide) yarn channels give poor results. The remaining nozzles all produce intermingled yarns with nip frequencies between 80 to $100 \mathrm{nips} / \mathrm{m}$ over a substantial part of the operating range considered here. Comparison on the basis of nip frequency as a function of power consumption favors nozzle designs with small air inlets. Nozzles with $0.7 \mathrm{~mm}$ inlet widths give the highest nip frequency in conjunction with low power consumption. However, the performance of nozzles with small air inlets is sensitive to yam channel shape The nozzles with large air inlet slot width are less sensitive to yarn channel shape, but consume more power. Air vents do not improve the performance of our rectangular nozzles and lead to increased air and power consumption.

The comparison of our experimental nozzles with four industrial nozzles reveals that the industrial nozzle with the smallest air inlet area gives low nip frequencies; the remaining nozzles give nip counts comparable to those for rectangular nozzles with similar air inlet areas. The performance of the rectangular nozzles compares well with the nonrectangular industrial nozzle s. Nozzles with rectangular yarn channels can be designed to perform as well as the best industrial nozzles.

Nozzles with rectangular yarn channel cross sections and extended air inlet holes generally perform successfully. The design with an extended inlet hole covers the entire width of the yarn channel, which enables all constituent filaments of the yarn to be continuously subjected to the incoming air flow. Our two-piece design of nozzle base and extended air inlet also eliminates the need for precise adjustments of the relative positions between base and cover. Control of the yarn path by yarn guides also appears to play an important role in ensuring the consistency and stability of the intermingling process. Furthermore, this arrangement significantly reduces noise.

Our present database only spans a limited number of designs, all with an identical length of $20 \mathrm{~mm}$ and a perpendicular air inlet. We are planning further work to test these conclusions over a wider range of geometric parameters for rectangular nozzles and also to demonstrate their validity for nozzles with different yam channel cross-sectional shapes such as circular and triangular.

\section{Literature Cited}

1. Basu, S. K., Intem1ingling Process, Man-Made Textiles Ind. 32(6), 223- 228, 240 (1989)

2. Demir, A., Intermingling/Interlacing: A Broad Survey, in "Proc. Int. Conf. Air-Jet Texturing \& Mingling/Interlacing," Loughborough University of Technology, Loughborough, U.K., 1989, pp. 41-64. 
3. Dorney, R. A., Demir, A., and Acar, M., A Study of Mingling Nozzle Noise Characteristics, in "Proc. Int. Conf. Air-Jet Texturing and Mingling/Interlacing," 1989, pp. 279-306.

4. DuPont De Nemours, U.S. patent 2 985995, 1961.

5. Iemoto, Y., Chono, S., and Sawazaki, K., Study on Interlaced Yarn, Part 1: Effect of Air Pressure, Air Flow Rate, Yarn Speed and Feed Ratio on Number of Tangles and Limit For Processing Interlaced Yarn, J. Textile Ma ch. Soc. Jpn. Trans. 35(1), 1- 5 (1989).

6. Lazauskas, V., Lukosaitis, A., and Matukonis, A., Effect of the Design Parameters of the Aerodynamic Device on the Tanglelacing Intensity of Filament Yarns, Tekh. Tekstil. Prom. (3), 27- 30 (1987).

7. Luenenschloss, J., and Zilg, J. P., Intermingling of Filament yarns in an Air Stream, Chemiefas. Textilind. 32/ 82(3), 809-820, E91 (1982).

8. Schubert, G., Vortexing of Flat Yarns, Chemiefas. Textilind. 30/82(10), 820-823, E92-93 (1980).

9. Weinsdoerfer, H., Mechanism of the Intermingling of Filament Yarns, Chemiefas. Textilind. 31/83(3), 198-202, E2 l-22 (1981). 